\title{
Use of head injury instruction cards in accident centres
}

\author{
A. B. WARD*, A. M. BOUGHEY,*T. S. AUNG* \& K. \\ BARRETT $^{+}$ \\ ${ }^{*}$ Department of Rehabilitation Medicine, Haywood Hospital, Burslem, Stoke-on-Trent \\ and ${ }^{+}$Department of Psychiatry, University of Keele, Keele, Staffordshire.
}

\section{SUMMARY}

This study reports on the value of head injury instruction cards as purveyors of information to patients. Patients over 10 years old attending the North Staffordshire Royal Infirmary Accident and Emergency Department with a mild head injury were invited to attend a special brain injury follow-up clinic, where they were asked to complete a questionnaire. Patients failing to attend this clinic were contacted and asked to complete the questionnaire. This revealed that they were no less severely affected by the injury as the attenders. They were asked why they had not attended and a significant number of patients had no recall of being given a head injury instruction card on which the information of the follow-up clinic was given. Memory loss was the most likely cause of this and is more common than is widely appreciated in patients attending accident and emergency departments.

\section{INTRODUCTION}

Head-injury cards are usually given to the persons accompanying a head injured patient prior to their discharge from the A\&E department, or, less commonly, to the patient themselves, if they present alone. Their usefulness has never been studied in the U.K. yet they remain standard practice in A\&E departments. As part of a larger study, seven out of 1546 patients with a head injury referred themselves to a follow-up clinic. Many of those not attending for follow-up had no recall of receiving a head injury instruction card in the A\&E department and this study aimed to examine the effectiveness of these cards.

Correspondence: $\operatorname{Dr}$ A. B. Ward, Consultant Physician in Rehabilitation Medicine, Department of Rehabilitation Medicine, Haywood Hospital, High Lane, Burslem, Stoke-on-Trent ST6 7AG. 


\section{METHODS AND PATIENTS}

During a 3-month period, head injury cards contained a special telephone number for those who were still complaining of symptoms related to the head injury 1 week after the event. Those that made contact were reviewed in a head injury follow-up clinic 2 weeks, 6 weeks and 3 months after the event. Patients who had been admitted from the A\&E Department were given an appointment to attend the clinic on their discharge from hospital. Clinic attenders were interviewed by a research nurse, who completed a symptom checklist and collected demographic data. Patients with an ISS score of 16 and over were excluded from the larger study, as were patients under the age of 10 years (reliable information from a questionnaire being unlikely in the latter group).

Head-injured patients who did not make contact were traced and asked why they had not requested a follow up appointment for persistent symptoms at 1 week. A total of 171 patients were contacted at 2 weeks to ascertain their symptom score (each symptom on the main study's questionnaire carried a score of 1 , totalling 30 in all) and asked if they had received a head injury instruction card in the A\&E Department.

\section{RESULTS}

Of the 171 questionnaires sent to those who had not made contact, 87 responded $(50.9 \%)$. Fifty-six reported they had received a head injury card, with details of the follow-up clinic on it and 31 had no recollection of being given a card. Within 2 weeks of the injury, two patients $(2.3 \%)$ had returned to the A\&E Department and $13(14.9 \%)$ had contacted their general practitioner (G.P.) (with one person seeking help from his G.P. for depression, of which the relevance to the head injury is unknown). Symptom scores were 5.32 for those cognisant of the head injury card and 5.9 for those not knowing of the card, compared to 10.5 for the clinic attenders. Memory problems were present in $26.8 \%, 35.6 \%$ and $25.0 \%$ of the non-attending groups and patients respectively.

\section{DISCUSSION}

The finding that over one third of head-injured patients had no recall of receiving a head injury instruction card on discharge from A\&E is surprising. Possible explanations are that A\&E staff did not issue cards, relatives receiving cards did not inform the person they had been given a card or the head-injured patient had memory loss for this aspect of his/her management. It is standard practice for A\&E staff to issue head injury instruction cards, along with verbal instructions of what symptoms to look for during the first $24 \mathrm{~h}$. The staff are well trained in this and compliance by them was successfully tested. On interview none needed any prompting about issuing such cards. Although a few patients may 'get away' 
when the department is extremely busy, it is most unlikely to account for the numbers seen. Similarly it is unlikely that relatives/carers would not have told the patient about receiving head injury cards.

The fact that so few patients returned to the A\&E Department with symptoms or attended the review clinic may indicate the advice is reassuring, symptoms are not bad enough to warrant further re-assurance, or patients did not perceive their symptoms as a problem or related to their head injury.

We conclude that a significant number of apparently minor head-injured patients have a memory deficit and may not remember being given a head injury instruction card. A brain injury can cause a pronounced impairment of recent memory without other neurological signs (Fisher, 1966; Jennett, 1976) and many patients will have little or no recall of receiving attention or instruction thereafter. This is confirmed in other studies (Rimel et al., 1981) and, in one, written discharge instructions required a level of comprehension greater than that of the population receiving them (Powers, 1988). In Canada, a literacy level of Grade 9 was required to understand the card, but poor compliance in reading the card was probably the most common cause of poor recall of written instructions, (Warren \& Kissoon, 1989). The value of head injury instruction cards is questionable and targetting of patients at risk may require further studies.

\section{ACKNOWLEDGEMENT}

Thanks is given to the Trustees and Secretary of the Nuffield Provincial Hospitals Trust for their support of this work.

\section{REFERENCES}

Fisher C. M. (1966) Concussion Amnesia. Neurology 16, 826-830.

Jennett B. (1976) Early complications after mild head injuries. New Zealand Medical Journal 84, 144-147. Powers D. P. (1988) Emergency Department patient literacy and the readability of patient directed materials. Annals of Emergency Medicine 17, 124-126.

Rimel R. W., Giordani B., Barth J. T., Boll T. J. \& Jane J. A. (1981) Disability caused by minor head injury. Neurosurgery 9(3), 221-228.

Warren D. \& Kissoon N. Usefulness of head injury instruction forms in home observation of mild head injuries. Paediatric Emergency Care 5, 83-85. 